\title{
Analysis on the Construction of Core Competence of Small and Medium-sized Cross-border E-commerce Enterprises
}

\author{
Liyan Jiao \\ Jilin Vocational and Technical Institute of Communications, Changchun, Jilin, China \\ jly8188@163.com
}

Keywords: construction, core competence, small and medium-sized cross-border e-commerce enterprises

\begin{abstract}
This paper focuses on the competitiveness enhancement of SMEs under the cross-border e-commerce development model, introduces the opportunities and problems existing in the implementation of cross-border e-commerce in SMEs, and proposes how to improve the competitiveness of SMEs based on cross-border e-commerce.
\end{abstract}

\section{Introduction}

Under the current complicated and severe foreign trade situation, the traditional foreign trade model has problems of over-reliance on traditional sales, closed buyer demand, long order cycle, and low profit margin. These problems restrict the development of SMEs' import and export trade. The operating model of cross-border e-commerce is based on the Internet, which is reshaping the international trade chain of SMEs. Cross-border e-commerce has broken the foreign marketing channels under the traditional foreign trade mode, enabling SMEs to directly face individual wholesalers and even consumers, effectively reducing the intermediate links and commodity circulation costs, and saving the intermediate link costs to improve the company's The ability and the consumer to get benefits are possible. Before 2012, China's traditional foreign trade enterprises and traditional manufacturing enterprises had little involvement in the cross-border e-commerce industry. Around 2013, traditional enterprises have joined the field, and cross-border e-commerce has gradually been valued by traditional enterprises and has become an important choice for traditional enterprise development. In addition, the financial crisis has brought about a big impact on the "container-style" traditional large-value trade, but at the same time promoted the development of cross-border e-commerce small wholesale and retail industry with online transactions as the core. SMEs are an important part of the national economy. As the competition in the international market becomes more and more fierce, the practical problem that SMEs need to face is how to survive and develop better in this tide. With the advent of cross-border e-commerce, SMEs have broken through the limitations of traditional factors and found new opportunities for SMEs to stand on the same starting line with large enterprises.

\section{Overview of Cross-border E-commerce}

Cross-border e-commerce definition: The meaning of cross-border e-commerce can be summarized in both broad and narrow sense. In a narrow sense, cross-border e-commerce is basically equivalent to cross-border retail. Cross-border retail refers to the transaction between merchants and consumers through cross-border e-commerce platform and online payment, and finally the products are delivered to consumers through international logistics. Broadly speaking, cross-border e-commerce is basically the same as foreign trade e-commerce, specifically refers to the electronic display, negotiation and transaction links in the traditional import and export trade through e-commerce, and delivered through cross-border logistics. 


\section{The Status Quo of Cross-border E-commerce Development}

After more than ten years of cross-border e-commerce development, the entire industry has experienced the exploration stage of the early information release platform, the trading platform operation stage and the recent B2C rise and rapid development stage. The cross-border e-commerce industry at each stage presents different Features. In the past two years, as the society's attention to cross-border e-commerce has been continuously improved, and the cross-border e-commerce participants have jointly promoted the development of the industry, the entire cross-border e-commerce industry has begun to show some new features. The participants in cross-border e-commerce mainly focus on small grassroots enterprises, network operators and individual merchants. After 2013, mainstream participants in traditional trade, such as foreign trade enterprises, brand merchants and factories, began to enter this field. Gradually moving towards large-scale operation; cross-border e-commerce enterprises and service enterprises continue to extend to other links in the industrial chain, integrating multi-party resources to provide all-round integration on issues related to customs clearance, logistics, and payment that affect cross-border e-commerce development. Services, new service providers are also emerging, and the service chain of the entire industry chain and ecosystem is becoming clearer and more complete.

\section{Analysis of the Opportunities of Cross-border E-commerce for SMEs}

On the one hand, the development of cross-border e-commerce can reduce the transaction costs of SMEs. Under the cross-border e-commerce model, enterprises can rely on the Internet information management platform to achieve the procurement of raw materials in a wider market and region, and reduce the procurement cost of enterprises. And transaction costs, to improve the profitability of enterprises have positive significance. On the other hand, the implementation of cross-border e-commerce can also effectively reduce the marketing costs of SMEs. Cross-border e-commerce can ensure that SME managers rely on Internet technology for marketing and product marketing, which can greatly reduce the intermediate transaction links, and also help direct communication and communication with consumers, saving on the basis of streamlining the transaction process. The marketing cost of the enterprise. Rely on the establishment of a comprehensive cross-border e-commerce website and other related marketing platforms, timely release and promotion of products, and online after-sales service and information technology support, to facilitate product promotion and marketing. In addition, SMEs can achieve unified and centralized procurement management on the basis of cross-border e-commerce platform, which helps to strengthen cooperation with suppliers, and relies on the strengthening of cooperation to realize information processing and information transmission. Achieving precise control of raw material inventory has important guiding significance. SME managers rely on the management of inventory to reduce their own business risks.

Being able to improve the transaction efficiency of small and medium-sized enterprises the small amount of business is the main problem in the production and operation of small and medium-sized enterprises. Relying on cross-border e-commerce can largely break through the space and time constraints, and have the advantage for enterprises to expand their own market space. Relying on online transactions can break through the original geographical and time constraints to achieve all-weather information and product services. Relying on the e-commerce platform, it can simplify the trade process, and can quickly process different transaction information, which helps to improve transaction efficiency, reduce the probability of human error, and provide customers with more precise and concise transactions. Enhancing customer satisfaction can help increase the number of orders and trading opportunities for SMEs, which can largely compensate for the small problems and shortcomings of SMEs.

Helping to expand the marketing scope of SMEs As an information dissemination channel and marketing channel, the Internet has many advantages, and can realize the combination of multiple media, no time and space constraints, and achieve multi-party interaction. It can realize the 
economical and convenient simplification of trading activities. Especially with the continuous popularization of cross-border e-commerce for SMEs, the proportion of online marketing has been continuously improved, and the shortage of funds and talents can be solved while getting rid of the limitations of traditional markets.

\section{Problems in the Development of Cross-border E-commerce for SMEs}

The development of cross-border e-commerce is closely related to the development level of information network technology, international logistics, electronic payment, and financial services. Due to the different degrees of development of information network technology and international logistics in various regions, the degree of development of cross-border e-commerce is also different. Cross-border e-commerce service enterprises are mainly distributed in areas with developed economy, smooth traffic and frequent trade.

In the context of traditional economic theory, the development of SMEs is subject to financial capacity. Also in the business process of cross-border e-commerce, sufficient funds will ensure that SMEs can carry out a series of commercial activities from marketing to customs clearance to delivery of goods. In addition, the environment of the entire network hardware and software directly affects the development of cross-border e-commerce for SMEs. From network infrastructure to cross-border logistics, international electronic payment, and improvement of the policy environment, a large amount of funds are required. In the cross-border e-commerce environment, SMEs need to solve the problem of incomplete capital to enhance the competitiveness of enterprises in the big environment, and the corporate concept problems they face need to be changed. Cross-border e-commerce needs to be recognized and adopted by most SMEs. If the original concept is maintained and the old concept is used to treat cross-border e-commerce, the result will be greatly deviated from expectations. For example, some companies believe that cross-border e-commerce is based on the network and is virtual and there are many unsafe factors.

\section{Measures to Improve the Competitiveness of SMEs under Cross-border E-commerce}

First, actively create a good cross-border e-commerce development environment, and effectively enhance government support. At present, there are still many problems and shortcomings in the development of cross-border e-commerce in China's SMEs. These problems and defects have greatly restricted the competitiveness of SMEs. The reason why there are difficulties in cross-border e-commerce is largely due to the time lag of the existing export policies and regulations under the current trade model, and it is difficult to fully adapt to the trade development model under the new situation. At present, the cross-border e-commerce retail export policy implemented in China began in April 2014. Under this policy environment, the coordination between various relevant government departments needs to be further strengthened. It is necessary to develop cross-border e-commerce around the new situation. The model develops new incentive policies to better promote the development of cross-border e-commerce for SMEs. It needs to be coordinated in various aspects such as credit, logistics and payment. Relying on the construction of pilot cities and demonstration cities, we can effectively solve the problems and deficiencies that may arise in the development of cross-border e-commerce. Under the policy support of relevant government departments, we should coordinate and participate in the development of taxation, customs, banking, insurance, after-sales and related certification institutions around the development theme of SME business trade, and jointly build a credit evaluation system for SMEs. . In addition, in order to better promote the development of cross-border e-commerce in China, government departments should also actively cultivate e-commerce enterprises with good reputation and influence, and promote the common development of cross-border e-commerce and electronic payment.

Second, further strengthen the construction of cross-border e-commerce talents for SMEs. The construction of talent team is an important foundation and guarantee for the development of e-commerce for SMEs, especially cross-border e-commerce. At present, many SMEs have unclear problems in their own positioning. There are many shortcomings in the operation and maintenance 
and daily management of online stores and websites. These shortcomings are largely due to the cross-border of SMEs. E-commerce talent construction can't keep up. In order to realize the development of cross-border e-commerce, SMEs need to strengthen the construction of the talent team, provide sufficient intellectual support, and display themselves in a higher posture. It should be noted that, unlike traditional domestic market enterprises, SMEs that conduct market trade around cross-border e-commerce face the international trade arena. Customers come from all over the world, which requires SME managers to carry out Cross-border e-commerce trade should pay full attention to and understand the culture, language, religious beliefs and customs of different countries. These have the potential to increase the uncertainty and risk of cross-border e-commerce for SMEs. Based on this, SME managers need to master relevant knowledge and skills such as logistics, customs clearance, online payment, etc., strengthen the construction of talent team, and rely on human resources construction to promote the core competitiveness of SMEs.

Third, give full play to its own advantages and actively seek a cross-border e-commerce development model suitable for its own development. Combined with management practices, it can be found that consumers or buyers tend to pay more attention to whether sellers can satisfy their own purchasing needs when purchasing products, and pay more attention to the reputation of suppliers and the quality of products. SME managers need to focus on product quality, product price, follow-up quality service and product supply chain, etc., in the product quality management, can be combined with third-party guarantees for product quality management. In addition, SMEs engaged in cross-border e-commerce, need to make full use of cross-border e-commerce platform, effectively take advantage of its fast and small spirit, take the road of specialization, realize the development path of customization, branding and specialization, relying on High quality and low price, good faith and excellent service have won praise from consumers. SMEs should also pay attention to network channels to further develop overseas markets, expand their international market scope and consumer customers, and rely on cross-border e-commerce platforms to promote their competitiveness.

\section{Conclusion}

While the overseas sales market of SMEs continues to expand, it will also face some difficulties and challenges. As the competition becomes more and more fierce, the production cost of products will also rise. Based on this, SME managers need to fully utilize and develop the advantages brought by cross-border e-commerce platform around their own development needs and industry characteristics, actively expand the international market, enhance their competitive strength, and analyze and grasp their own market positioning. Achieve better and faster development.

\section{References}

[1] Dong Shaobin. E-commerce operation mode and path selection of small and medium-sized enterprises [J]. Enterprise Economy, 2011, (11): 93-96.

[2] Dong Zhiyi. Let Chinese services go to the world [J]? Management World, 2012, (02): 1-7.

[3] E Libin, Huang Yong listen. New ways of international trade: the latest research on cross-border e-commerce [J]. Dongbei University of Finance and Economics, 2014, (03): 22-31.

[4] E Libin, Liu Zhiyong. Research on cross-border e-commerce sunshine clearance [J]. International Trade, 2014, (09): 32-34.

[5] Gao Gongbu, Jiao Chunfeng. China's SME E-commerce Internationalization Development Strategy [J]. World Economic and Political Forum, 2005, (02): 117-125. 